\title{
"OI, MEU NOME É BETTINA": \\ A VOZ E A VEZ DO HOMO OECONOMICUS NO NOVO GOVERNO BRASILEIRO
}

\author{
"HI, MY NAME IS BETTINA: \\ THE RISE OF HOMO OECONOMICUS IN THE \\ NEW BRAZILIAN GOVERNMENT
}

\section{Carlos Renato Lopes*}

\section{RESUMO}

O artigo propõe uma leitura do momento inicial do governo de direita ora vigente no Brasil, sugerindo a emergência de uma forma particular de populismo que, sustentada por uma lógica neoliberal de funcionamento da sociedade, constitui terreno fértil para o florescimento de um discurso de empreendedorismo e sucesso financeiro ao alcance de qualquer indivíduo. Tal configuração, que chamamos aqui de populismo neoliberal, promove em sua esteira a construção de formas específicas de subjetividade. Para ilustrar a discussão, analisamos dois anúncios virais de uma consultoria de investimentos veiculados no YouTube que encenam a nova ordem político-econômica de forma problemática e geradora de resistências.

Palavras-chave: populismo; neoliberalismo; bomo oeconomicus.

\section{ABSTRACT}

The article proposes a reading of the initial moment of the current right-wing government in Brazil, suggesting the emergence of a particular form of populism which, supported by a neoliberal logic of the functioning of society, constitutes fertile ground for the flourishing of a discourse of entrepreneurship and financial success at any individual's reach. Such a configuration, which we hereby name neoliberal populism, fosters in its wake the construction of specific forms of subjectivity. To illustrate this discussion, we analyzed two viral ads from an investment consulting firm on YouTube which enact the new political-economic order in a problematic and resistance-generating fashion.

Keywords: populism $i$ neoliberalism, bomo oeconomicus.

\section{INTRODUÇÃO}

O ano de 2019 marca o início do primeiro governo reconhecidamente de direita no Brasil em muitos anos. Se a contraposição esquerda versus direita parecia estar discursivamente esvaziada em períodos anteriores de nossa história - ainda

\footnotetext{
* Universidade Federal de São Paulo, UNIFESP, Guarulhos, SP, Brasil. carelo@uol.com.br Orcid: https://orcid.org/0000-0002-8814-1208
} 
que se possa sempre atribuir, por orientação ideológica e em alguns casos com certa controvérsia, uma ou outra denominação aos governos que tivemos (Lula era de esquerda, FHC de centro, Collor de direita...) - tal distinção retorna com forte poder de afirmação com a queda de Dilma Rousseff, há quatro anos. Após treze anos do Partido dos Trabalhadores no poder, período em que essa própria formulação governo de esquerda - figurava menos como o grande palco de batalhas ideológicas que hoje se verifica do que propriamente uma tomada de posição no espectro político-partidário, sobreveio um governo "de transição", com Michel Temer, e em 2018 a eleição de Jair Bolsonaro.

Assim, 2019 vê tomar forma, em seus primeiros passos, um governo que se pauta, em recorrentes discursos oficiais, pela conjuração do "viés ideológico" das esquerdas materializada em várias de suas frentes: das relações internacionais à demonizada ideologia de gênero. Autoproclamado liberal na economia e conservador nos costumes, o novo governo guia-se por discursos revisionistas e por ações de desmonte do que identifica como um "aparelhamento ideológico" da esquerda no poder, bem como pela evocação de fantasmas do passado, como a ditadura, o AI5 e até mesmo o fascismo: uma espécie de substrato, tão frequentemente sugerido quanto negado, do pensamento bolsonarista de extrema-direita.

Embora o termo populismo não tenha sido comumente evocado para se referir às políticas do atual governo, pelo menos em seu início, é possível relacionar algumas características descritas na teoria política como marcas do populismo à forma específica com que tem se dado tal fenômeno no Brasil via articulação entre visão de Estado e política econômica - forma específica que chamaremos de populismo neoliberal. Este artigo busca traçar um esboço geral do funcionamento de tal articulação, tomando como objeto de análise dois anúncios de mídia social focados em finança pessoal. Começamos por delimitar o sentido de populismo do qual partimos e, na sequência, descrevemos o modo como o pensamento neoliberal se atualiza nesse cenário.

\section{POPULISMO COMO INSTRUMENTO DE ANÁLISE}

Para propor sua concepção própria de populismo, Laclau (2005) lança mão da noção de representação de diferenças pelo discurso. Diferenças são representadas em cadeias de signos que se opõem mutuamente, ao longo de um processo contínuo, local e historicamente constitiuído. A possibilidade de apreensão da totalidade do objeto real por meio desses signos jamais é atingida plenamente. Todavia, ao longo desse mesmo processo histórico, surge em algum momento "a possibilidade de que uma diferença, sem deixar de ser uma diferença particular, assuma a representação 
de uma totalidade incomensurável"11 (p. 70). Quando isso ocorre, dá-se o que o autor entende por begemonia. Um objeto local ascende, via discurso, ao patamar de universal na condição de significante vazio - com "sua própria particularidade dando corpo a uma completude inatingível"2 (p. 71).

O fato de tal completude ser impossível não significa, no entanto, que ela deva ser afastada como falha, mas sim entendida como um borizonte, uma abertura.

Se a sociedade fosse unificada por um determinado conteúdo ôntico - uma determinação em última instância pela economia, o espírito de um povo, uma coerência sistêmica, ou o que seja - a totalidade poderia ser diretamente representada no nível estritamente conceitual. Dado que este não é o caso, uma totalização hegemônica requer um investimento radical - isto é, um investimento não determinável a priori - e um engajamento em jogos de significação que são muito distintos de uma apreensão puramente conceitual. ${ }^{3}$ (LACLAU, 2005, p. 71)

É o que se dá com o populismo. Laclau não o concebe como um tipo de movimento, fundado numa base social comum ou numa orientação ideológica particular, mas sim como uma lógica política. O populismo não se define, de antemão, pela separação entre dois blocos homogenêos e antagônicos - de um lado, "o povo puro', de outro 'as elites corrompidas" - buscando ser a expressão geral da vontade popular (p. 117). Tal configuração dicotômica poderia, a princípio, se observar em qualquer regime político, de qualquer época. Afinal, relações desiguais de poder e seus correspondentes conflitos de interesses atravessam o corpo social de forma constitutiva. O que Laclau sinaliza aqui é para a possibilidade de se manter o termo populismo como um significante flexível, e em constante atualização, dos modos como se articulam as políticas públicas às complexas demandas sociais. A linguagem do discurso populista -quer de direita quer de esquerda - será sempre imprecisa e oscilante, justamente por tentar operar performativamente dentro de uma sociedade que é largamente heterogênea. Antes de serem falhas cognitivas, a vagueza e a imprecisão são componentes essenciais de qualquer operação populista (p. 118).

Dado que o populismo pode enquadrar "o povo" de modo genérico o suficiente para apelar às mais diferentes demografias e articular suas demandas, ele pode gerar um senso de identidade compartilhada entre grupos distintos e reforçar

1. "the possibility that one difference, without ceasing to be a particular difference, assumes the representation of an incommensurable totality."

2. "its own particularity embodying an unachievable fullness."

3. "If society were unified by a determinate ontic content - determination in the last instance by the economy, spirit of the people, systemic coherence, or whatever - the totality could be directly represented at the strictly conceptual level. Since this is not the case, a hegemonic totalization requires a radical investment - that is, one that is not determinable a priori - and engagement in signifying games that are very different from purely conceptual apprehension." 
o apoio a causas comuns (MUDDE \& KALTWASSER, 2017, p. 9). Da mesma forma, o potencial derivativo do significante povo permite que "até mesmo demandas e mazelas genuinamente populares acabem sendo representadas por forças iliberais e não-democráticas, ou se tornem reféns de dinâmicas institucionais autoritárias" (STRAVAKAKIS, 2017, p. 7) ${ }^{4}$.

Não se trata, portanto, de enfatizar supostas características que definiriam um populismo de esquerda (digamos, os que já tivemos e temos na América Latina) ou um populismo de direita (por exemplo, os que estão em ascensão na Europa, mas também nas Américas). Estas existem, obviamente, com suas especificidades locais e suas variantes e interseções. O que importa aqui é entender o conceito de populismo como um instrumento que nos auxilie a gerar inteligibilidades sobre as formas como, no Brasil de Bolsonaro, a política adentra a vida das pessoas, quer por ação direta de medidas, legislações ou reformas, quer pela construção de um imaginário da própria vida em sociedade, seus valores e prioridades, suas (novas) restrições e suas (novas) possibilidades de articulação. Dado que, no caso específico do ideário político liberal e de direita, propõe-se que o Estado seja mínimo e interfira o menos possível nas liberdades individuais, o populismo pode nos auxiliar a entender também as ausências e silenciamentos (mas também as brechas) no discurso em torno do que pode ou não pode promover melhoria na vida de todos os cidadãos.

Outra decorrência de uma visão instrumental de populismo é a possibilidade de os atores políticos o articularem com diferentes "ideologias hospedeiras" ${ }^{\prime 5}$ (MUDDE \& KALTWASSER, 2017, p. 40), tais como as renovadas formas de nacionalismo (incluindo o patriotismo cívico-militar verde-amarelo ressignificado pelo Bolsonarismo, o ruralismo (com as relacionadas políticas de meio-ambiente e da questão indígena no Brasil), o socialismo (como nêmesis ideológico à esquerda) e, onde nossa análise irá focar, o neoliberalismo (o que inclui uma visão para além do mercado). Para que ganhem tração e sigam operando, tais ideologias e os sujeitos por elas posicionados, frequentemente em mútuo conflito, precisam permanentemente jogar os jogos de significação no esforço de assegurar alguma possível hegemonia. Nesses jogos de significação, destaca-se o florescimento de um discurso neoliberal de empreendedorismo do indivíduo que, antes de independer do funcionamento seletivamente "mínimo" do Estado (cf. RYDGREN, 2017) no governo de turno,

4. "even genuine popular grievances and demands can end-up being represented by illiberal and antidemocratic forces or becoming hostages of authoritarian institutional dynamics."

5. "host ideologies" 
vem articular-se a ele de modo orgânico e coerente - ainda que tal articulação não seja explicitamente discursivizada, como veremos na análise.

\section{HOMO OECONOMICUS E POPULISMO NEOLIBERAL}

O atual governo foi eleito com a promessa de um poder autônomo do Ministério da Economia, sob o comando do chamado "superministro" Paulo Guedes - o primeiro a ser previamente definido, ainda durante o período de campanha eleitoral em 2018. Oriundo da chamada Escola de Chicago, Guedes propôs desde sempre uma agenda neoliberal de incentivo ao livre comércio, privatizações, regulação mais severa de auxílio financeiro a programas sociais em suma, a diminuição da presença do Estado como sustentáculo da economia. Sua primeira grande tarefa foi a de ter aprovada uma Reforma da Previdência cujo apoio de setores de elite e, majoritariamente, da imprensa foi decisivo para sua efetivação. Conservador nos costumes, liberal na economia: este se tornou o mote consensual das análises do governo que se iniciava. Se mesmo nos governos de esquerda a lógica do neoliberalismo se fazia presente em políticas econômicas de incentivo e ampliação do poder de consumo das classes mais populares, estas não necessariamente se inscreveram na memória discursiva como sendo neoliberais. Mais precisamente, a tentativa desses governos foi de aliar os preceitos do neoliberalismo a uma visão social democrata de Estado que promovesse avanços em políticas de inclusão social resultando na redução da desigualdade socioeconômica.

Reduzir a desigualdade social, no entanto, não figura no governo Bolsonaro como uma meta prioritária, a julgar pelos discursos oficiais. Conforme esclarece Brown (2015), o neoliberalismo almeja, dentre os seus preceitos, o fim da redistribuição da riqueza como política econômica ou sociopolítica em favor de uma "crescente dominância do capital financeiro sobre o capital produtivo na dinâmica da economia e da vida cotidiana" ${ }^{\prime \prime}$ (p. 28). Toda e qualquer necessidade ou desejo humano se converte em empreendimento rentável. E os indivíduos, em tal processo, são convocados a se tornarem empreendedores de si mesmos, sustentados por seus próprios méritos e cada vez menos dependentes de políticas de seguridade social, ainda que na informalidade das atividades profissionais "sem carteira assinada".

Assim, o neoliberalismo ganha forma como "uma racionalidade de governança que estende uma formulação específica de práticas, métricas e valores

6. "increasing dominance of finance capital over productive capital in the dynamics of the economic and everyday life." 
econômicos para toda dimensão da vida humana"7 (BROWN, 2015, p. 30). A ubíqua economização da vida humana não se restringe ao fato de que tudo se torna marquetizado, no sentido estritamente comercial do termo. Mais particularmente, trata-se de disseminar um modelo de mercado para todas as esferas e atividades, constituindo os indivíduos ostensivamente como agentes de mercado - ou, como prefere Brown, bomo oeconomicus.

O termo bomo oecnonomicus define o indivíduo dimensionado por seu potencial como "capital humano". Visto como autônomo e responsável por si mesmo, o indivíduo se apresenta agora como empreendedor de si mesmo. Encontrase disponível no mercado na medida em que se "equipa", por esforço e mérito próprios, de habilidades e ferramentas que o tornarão mais ou menos valioso. Ao mesmo tempo, torna-se dispensável e substituível por qualquer outro indivíduo que demonstre valor equivalente. Conforme aponta Brown (2015, p. 38), em "uma democracia composta de capital humano figuram ganhadores e perdedores, e não um tratamento ou proteção iguais" ${ }^{\prime \prime}$. Onde predomina o bomo oeconomicus, a própria dimensão do político se configura em termos econômicos, e os "fundamentos para uma cidadania voltada à coisa pública e ao bem comum se esmaecem" ${ }^{\prime \prime}$ (p. 39). Ou como descreve Chun (2016):

Ao se reduzir ou, em alguns casos, abandonar a responsabilidade do Estado pela seguridade e bem-estar públicos, a governança neoliberal enreda os indivíduos na posição subjetiva de se responsabilizarem unicamente por seu bem-estar e desenvolvimento. Em outras palavras, o ônus recai sobre o indivíduo de encontrar os meios e recursos para se aprimorar e se adaptar sozinho, e com pouco ou nenhum apoio fornecido pelo governo..$^{10}$ (CHUN, 2016, p. 562-3)

Se nossa hipótese de que a racionalidade neoliberal se conjuga (antes de se opor) à forma específica de populismo observada no atual governo de direita brasileiro, então vemos ecoar as palavras acima em diversas manifestações públicas de autoridades como o ministro Paulo Guedes, que em uma coletiva de imprensa em fevereiro de 2020 referiu-se aos servidores públicos como parasitas, cujos privilégios precisam ser revistos. Na mesma linhagem, e praticamente na mesma semana, se

7. "a governing rationality extending a specific formulation of economic values, practices, and metrics to every dimension of human life."

8. "A democracy composed of human capital features winners and losers, not equal treatment or equal protection."

9. "the foundation vanishes for citizenship concerned with public things and the common good."

10. "In reducing, or in some cases abandoning, state responsibility for public well-being and welfare, neoliberal governance enmeshes individuals in the subject position of being solely responsible for their well-being and development. In other words, the onus is on the individual to find the means and resources to improve and adapt on their own and with little, if any, government-funded support." 
dá a declaração do presidente Bolsonaro segundo a qual pacientes HIV positivos (também referidos por ele pelo já proscrito termo "aidéticos") representam despesa para o governo ${ }^{11}$. Por outro lado, a declaração de Guedes, na semana seguinte, de que dólar alto é bom, dado que na época do real forte até empregadas domésticas viajavam à Disney (numa "festa danada") não parece sugerir que o Estado esteja disposto a estimular a conquista da prosperidade financeira e o consequente aumento do padrão de consumo para todos os brasileiros.

É preciso depender menos do Estado, nos diz a racionalidade populista neoliberal. E dentro dessa racionalidade, a necessidade de buscar fontes de renda autônomas torna-se imperativa. Eis que o mercado de aplicações e investimentos financeiros pode vir a ganhar espaço sem precedentes. Hoje, como antes, é possível investir em uma gama ampliada de opções, com resultados mais ou menos assegurados; entretanto, o acesso às informações via consultorias financeiras tornase um diferencial dado que, a princípio, qualquer cidadão com um pouco de tempo, disciplina e capital pode embarcar na promessa de ganhos fáceis e relativamente rápidos de seus investimentos. Qualquer pessoa pode ser um empreendedor, não importando em que escala e em que condição socioeconômica se encontra. Isso envolve, como já sugerido, não somente quanto dinheiro alguém está disposto a perder ou ganhar, mas também como se pretende em um espectro mais amplo, gerir a economia e a saúde familiares, nortear a decisão de ter ou não filhos e bancar seus estudos, aproveitar o tempo livre, planejar a aposentadoria - enfim, todas as dimensões da vida social, diretamente ligadas ou não à monetização (BROWN, 2018; LORENZINI, 2018).

A suposta liberdade de escolha quanto aos modos de gerir as próprias finanças resulta da forma como o neoliberalismo deixa de exercer um poder gestor sobre os corpos produtivos e passa a promover mecanismos de ação sobre o si próprio. Isso se dá de tal modo que os indivíduos interiorizam os mecanismos de poder como sendo geradores de sua própria liberdade, numa "engenharia de liberdade e exploração"12 (HAN, 2017, p. 28) complexa e só aparentemente contraditória. Passemos nesta conexão a nosso objeto de análise, que lançará uma luz sobre como tal ordem de coisas tem se materializado no discurso.

11. Incluam-se aí os repetidos cortes de bolsas na educação superior e no programa Bolsa Família. 12. "engineering of freedom and exploration" 


\section{O CASO BETTINA}

Em março de 2019, um anúncio ${ }^{13}$ da empresa de consultoria financeira Empiricus emerge na internet e, com ele, uma personagem cujo nome seria lembrado por todo o resto do ano: Bettina. A seguir, a transcrição do texto.

\section{Tabela 1. Transcrição do texto do primeiro anúncio da Empiricus, março de 2019}

Oi, meu nome é Bettina, eu tenho 22 anos e 1 milhão e 42 mil reais de patrimônio acumulado. Desculpa a indiscrição, é que o tempo aqui em baixo não joga a meu favor e eu precisava chamar sua atenção. Ninguém acha normal eu ter juntado mais de 1 milhão de reais assim, tão nova e começando com muito pouco. Mas sabe o que que chama a minha atenção? É que o que eu fiz não é nenhum segredo. Eu vivo falando por aí, pra todo mundo: eu comprei ações na bolsa de valores. Não foi sorte, eu não herdei uma bolada e nem ganhei na loteria. Comecei com 19 anos e 1.520 reais. Três anos depois tenho mais de um milhão. Simples assim. Sabe qual o problema? A maioria das pessoas vai pular esse anúncio e continuar se chocando com histórias fora da curva, e a minoria vai clicar no botão azul que vai aparecer no fim desse vídeo. Se você for uma das pessoas que vai clicar no botão, você vai acessar o passo a passo que eu segui pra você chegar no seu primeiro ou próximo milhão. Os resultados, eu garanto, serão os mesmos. Não tem como ser diferente. Se você tiver as mesmas noções que eu tenho, vai lucrar proporcionalmente o mesmo que eu. Isso vale pras perdas também. É com você. Resultados diferentes exigem atitudes diferentes. Botão azul.

Inseridos de forma onipresente no início (mas também no meio e até mesmo no final) de vídeos no YouTube, anúncios como este são normalmente vistos como uma inconveniente interrupção comercial, semelhante à que ocorre na televisão. A diferença em relação às propagandas de televisão é que no YouTube a maioria dos anúncios, principalmente quando mais longos que 30 segundos, podem ser "pulados" após 5 segundos de exibição. A suposta liberdade de assistir aos vídeos sem tal interrupção torna-se, nesse contexto, um fator fundamental para a estratégia comunicativa dos produtores. É como se pular o anúncio fosse previsto como ação preferencial, com a maior parte dos espectadores indispostos a perder tempo com ele. Portanto, os primeiros segundos são essenciais, quer transmitindo imediatamente o ponto principal a ser vendido/anunciado, quer instigando o espectador a não pular e seguir vendo até o fim. É o que ocorre aqui quando Bettina, a jovem garota-propaganda da Empiricus, inicia o texto. Em pouco mais de 5 segundos, somos informados sobre seu nome, idade, e o principal: ela hoje acumula

13. Disponível em < https://www.youtube.com/watch?v=knIHvor2gHs > 
um valor patrimonial expressivo (para alguém da idade) e bastante preciso (o que parece lhe conferir mais credibilidade).

Logo em seguida, num breve e estratégico aceno metalinguístico, Bettina se desculpa pelo "incômodo" da interrupção esclarecendo que o tempo de que dispõe - tanto para transmitir sua mensagem quanto para evitar que o espectador a descarte - é curto demais. Para tal, utiliza a expressão "não joga a meu favor", sugerindo que se trata de uma disputa, uma competição entre ela (em nome da empresa) e o tempo/interesse escasso dos espectadores, os quais precisam ser seduzidos a continuarem a jogar.

Transcorridos os 5 segundos iniciais, tem sequência o relato testemunhal, dirigido a um "você" disposto a continuar a ouvir, se informar e, possivelmente, ser persuadido. Num primeiro movimento, Bettina evoca o estranhamento das pessoas - "ninguém acha normal" - a respeito da façanha de ter "juntado" mais de 1 milhão de reais, a partir de tão pouco -1.520 reais, conforme explicitado pouco depois - e com tão pouca idade. Destaca-se aqui o uso do verbo "juntar", inscrito em um registro um tanto coloquial, para aproximar o genérico público-alvo de sua experiência.

O modus operandi da referida conquista então se revela. E, segundo Bettina, nenhum grande segredo está envolvido. Ao contrário, ela compartilha "por aí, para todo mundo" que se trata de um investimento na bolsa de valores. $\mathrm{O}$ dinheiro não teria vindo de herança ou sorte na loteria, fatores que num primeiro momento quebrariam o "pacto" unindo o espectador e ela numa narrativa de possibilidade concreta. Afinal, trata-se aqui de vender uma ideia, um conceito, um produto. E o que se está vendendo aqui, fundamentalmente, é a narrativa de que qualquer pessoa pode atingir patamar semelhante ao de Bettina, dado que ganhar na loteria ou herdar uma grande soma da família ("uma bolada", ainda no registro coloquial) seriam possibilidades restritas a um número substancialmente menor de pessoas dentre as que a ouvem no momento.

O modo como a trajetória que se inicia nos 1.520 e se atualiza nos 1.042 .000 reais é narrada insinua, no entanto, que tal como ganhar na loteria ou herdar uma fortuna o feito de Bettina é bem simples, quase automático. "Comecei com 19 anos e 1.520 reais. Três anos depois tenho mais de um milhão. Simples assim." A sequência de três sentenças curtas, encadeadas numa lógica de causa-efeito, sugere que o grande salto de uma quantia a outra pode se dar em um período curto de tempo, progressivamente e sem obstáculos. "Simples assim." Silenciados estão aqui os passos seguidos. O que exatamente Bettina teria feito? Em que ações teria investido? Teria havido aportes adicionais ao longo do caminho? Silenciado está 
também o que uma subsequente investigação revelaria ter havido: a doação de um valor bem maior, por parte do pai da moça, somado aos 1.520 que de fato teriam sido o total de investimento com que ela sozinha contava. Portanto, o milhão não chegou tão rápido a partir de "meros" 1.520 reais. A narrativa está estrategicamente incompleta. Se há algum segredo, é o da lógica norteando o discurso neoliberal de que todos podemos lucrar bem, e muito, com o pouco que temos - talvez não 1 milhão em 3 anos, mas é isso, afinal, que está sendo apregoado no anúncio.

Seguindo a estrutura dialógica com o espectador, que pode (ainda?) estar se perguntando se deve crer no relato, Bettina enquadra a imaginada reação do espectador de forma binária: ou bem pulará o anúncio, chocando-se com uma "história fora da curva" (como a dela própria?), ou assistirá até o fim e clicará no botão azul a partir do que será possível obter informações mais detalhadas de como traçar uma trajetória afim. Caso se opte por esta última, Bettina garante, "os resultados serão os mesmos". Não tem como ser diferente." Com um simples "Botão azul", encerra-se o anúncio em pouco mais de 1 minuto de atenção dispensada. E com isso, é a imagem de Bettina como a bela jovem que nos convoca a ganhar dinheiro (rápido e fácil) tal como ela que se inscreve na memória - imagem que representa uma empresa de cujo nome, a propósito, não seremos informados até que sigamos o próximo passo e cliquemos adiante. "É com você".

Se o espectador tiver as mesmas noções que Bettina, lucrará (mas também poderá perder) também. Trata-se de um funcionamento lógico do capital gerando capital, supostamente imune a intempéries de ordem estrutural, como o cenário político-econômico de alto desemprego, por exemplo. $\mathrm{O}$ questionamento, contudo, não se apaga: o espectador médio pode até ter as mesmas noções que Bettina, mas terá ele o mesmo "empurrão" que ela obteve do pai afortunado? Bettina deixa o espectador "livre" para se informar mais, ou simplesmente descartar sua narrativa antes de ouvi-la até o fim ("É com você."). Nesse movimento, parece simultaneamente incentivar que se siga seu exemplo e se pondere sobre as perdas, ressaltando que os ganhos são proporcionais ao investido. A ponderação é tão importante quanto o incentivo. Porém, não terá sido essa a única fonte de uma possível má-interpretação da mensagem de Bettina. As reações vieram na forma de resistência, conforme mostraremos mais abaixo. Antes, no entanto, demos um salto de 7 meses (outubro de 2019) e acompanhemos uma nova mensagem de Bettina, em um segundo vídeo ${ }^{14}$ que virá como resposta / esclarecimento / retratação ao primeiro, mediante as manifestações surgidas.

14. Disponível em < https://www.youtube.com/watch?v=0wN6_3VjOfk > 
Tabela 2. Transcrição do texto do segundo anúncio da Empiricus, outubro de 2019

Oi, meu nome é Bettina, eu tenho 22 anos e eu quero te pedir desculpas. Por um motivo simples: a nossa relação começou de maneira errada. Por culpa minha. Na verdade, por culpa nossa. Quando você me viu pela primeira vez, naquele anúncio de menos de 1 minuto, eu não consegui mostrar pra você quem eu realmente sou. Pelo contrário, eu transmiti uma mensagem equivocada, que ou despertou ganância nas pessoas ou passou um recado distorcido, de que a minha evolução patrimonial aconteceu de forma fácil ou rápida. Não era essa a intenção, sinceramente. E, principalmente, não é essa a verdade. Mesmo naquela versão curta de anúncio que acabou viralizando, precisava ter ficado mais claro que houve outros aportes no meio do caminho. Agora, eu vim aqui por uma segunda chance, pra te mostrar quem eu realmente sou, quem a gente realmente é. Mas tem uma pergunta bastante importante que você deveria estar se fazendo: depois de tudo isso, o que teria acontecido se você tivesse apertado no botão "saiba mais" daquele meu anúncio? Eu tô aqui pra te mostrar isso.

Retomando, num tom mais contrito, os dizeres iniciais do primeiro vídeo, Bettina encadeia "tenho 22 anos" a uma oração coordenada que parece estabelecer um nexo causal: "e eu quero te pedir desculpas". Na memória recente de muitos espectadores, aquelas primeiras palavras ecoam já como sedimentadas, parafraseadas em tantos outros textos. Esses dizeres, portanto, são o dado. O novo é um pedido de desculpas e, por um "motivo muito simples": a relação entre Bettina e seus espectadores começou de forma errada - por culpa dela; "na verdade, por culpa nossa". Mas qual é a natureza dessa relação?

A narrativa segue na presunção de que houve uma falha de comunicação entre Bettina e seus interlocutores. E tal falha não se limitaria ao entendimento da "mensagem" propriamente dita que, segundo ela, pode ter sido interpretada de forma equivocada ou distorcida. A falha se dá pela impossibilidade de, em um vídeo de 1 minuto, Bettina mostrar aos seus interlocutores - ainda referidos como "você" - quem ela realmente é. É sintomático que o questionamento sobre sua identidade seja levantado aqui e repetido mais ao final do vídeo: "eu vim aqui por uma segunda chance, para te mostrar quem eu realmente sou, quem a gente realmente é". Emergem nesses trechos dizeres que poderiam perfeitamente estar inscritos no discurso amoroso - numa formação discursiva que mobiliza o conhecimento íntimo da pessoa amada e de si próprio, e que envolve segundas, terceiras chances para que o relacionamento "dê certo". Tal leitura se ancora numa aparente ambivalência em torno da expressão a gente. De quem se trata? A gente, empresa Empiricus e o que temos a lhe oferecer? Ou a gente, eu (Bettina) e você (meu interlocutor, potencial cliente-investidor)? 
De todo modo, tal ambivalência pode ser vista menos como uma "falha" de comunicação do que um "equívoco" no sentido psicanalítico em que o termo é mobilizado na Análise do Discurso (cf. PÊCHEUX, 1997). O equívoco materializa, no discurso, o modo de constituição da subjetividade próprio da formação ideológica em que se inscreve o neoliberalismo. Como já repetido, o neoliberalismo abrange todas as frentes da vida social, gerando investimentos, lucros e dividendos ao mesmo tempo que gera subjetividades, modos de existir que podem estar mais ou menos ligados às finanças propriamente ditas. Por essa leitura, quando Bettina se mostra investida em mostrar quem ela realmente é, é como se incluísse o interlocutor ("quem a gente realmente é") em sua empreitada. Somos o que compramos, somos o que investimos, somos a projeção de um êxito que é, no valor de face, um êxito financeiro $e$ também um êxito de "realização pessoal".

Se, todavia, Bettina se referia à Empiricus, pouco muda. O efeito de sentido que aqui desvelamos segue ecoando de alguma forma quando empresa, garota propaganda e cliente são constituídos como sujeitos de potencialidades - sujeitos livres, com iniciativa, empreendedores de si mesmos, irmanados (e em última análise "íntimos"), porém esvaziados de uma história sobre como ali chegaram e como o discurso nivelador da "igualdade de condições" os constitui de forma naturalizada, sem problematizações. Se problematizações houve, teriam sido dúvidas de quem preferiu reagir ao vídeo sem se "dar ao trabalho" de clicar no botão azul e seguir ouvindo. Mas Bettina está disposta a dirimir tais dúvidas (numa segunda chance). É basicamente por essa razão que um segundo vídeo foi feito. Outros vídeos vieram e virão, com ou sem Bettina. Não é Paulo Guedes ou Bolsonaro que diretamente intervêm nesse processo com suas políticas. É a lógica do que estamos chamando de populismo neoliberal - cujos princípios guiam e sustentam seu governo - que está em operação aqui: proliferando-se, ramificando-se, semeando em terreno fértil. É o neoliberalismo agindo sobre si mesmo: capital (humano) sobre capital (humano).

Os dois vídeos estrelados por Bettina forjam uma aproximação imaginária com seu público bem ao sabor da lógica neoliberal do bomo oeconomicus. Não importa se seus espectadores não se pareçam nem um pouco com ela (mulher, jovem, branca, bela,...), ou que venham de condições socioeconômicas e identitárias completamente distintas das dela. Eles estão em uma "relação que começou errada" mas que pode se consertar, dado que o que talvez tenha faltado são as informações técnicas necessárias para o engajamento dos espectadores e o potencial sucesso de um empreendimento mediado pela empresa anunciante. Tudo sem antes, porém, um "pedido de desculpas". 
Novamente, silenciados estão aqui fatores fundamentais para o sucesso ou fracasso da investida neoliberal. A distância entre ricos e pobres no Brasil seria desde já um fator preponderante para explicar por que muitos poucos compartilham do privilégio de Bettina para começar a jogar o jogo. Outro fator crescentemente observável no contexto populista-neoliberal do novo governo é a precarização do trabalho: o fato de que o empreendedorismo de si mesmo só pode existir, para um grande de número de trabalhadores, sob a forma de atividades precarizadas, isentas de seguridade e benefícios assegurados por leis - fenômeno que pode ser resumido pelo termo uberização (em referência ao serviço de transporte e entregas). Ainda nessa equação, há de se considerar o que Hardt e Negri (2012) apontam como uma das formas de subjetividade que definem o neoliberalismo e que por ele são potencializadas: a figura do devedor. Segundo os autores, ter dívidas tem se tornado uma condição geral da vida social, sendo praticamente impossível viver sem incorrer em dívida de alguma natureza: empréstimos, financiamento de estudos, crediários em lojas, tratamentos de saúde sem convênio (p. 10). Seriam os potenciais clientes da Empiricus cidadãos com dívidas, porém com disposição para arriscar e investir assim mesmo? Ou seriam apenas aqueles que não precisam se preocupar com tal questão e desejam multiplicar seus rendimentos? Dívidas freiam ou impulsionam o avanço da lógica neoliberal? Para concluir a discussão, apresentamos brevemente a seguir algumas das reações geradas pelo "fenômeno Bettina" nas quais parte desses silenciamentos ganha uma voz.

\section{REAÇÕES E RESISTÊNCIAS}

O primeiro anúncio com Bettina viralizou, como ela mesma enuncia no segundo vídeo. Todavia, a trajetória de Bettina não repercutiu como um caminho plausível ou sequer factível para um bom número de pessoas, a julgar pelos textos responsivos que foram surgindo na esteira do primeiro anúncio. Memes, paródias, entrevistas com a jovem em talk shows e programas de rádio, entre outras manifestações, atestam a popularidade problemática do "fenômeno Bettina". 


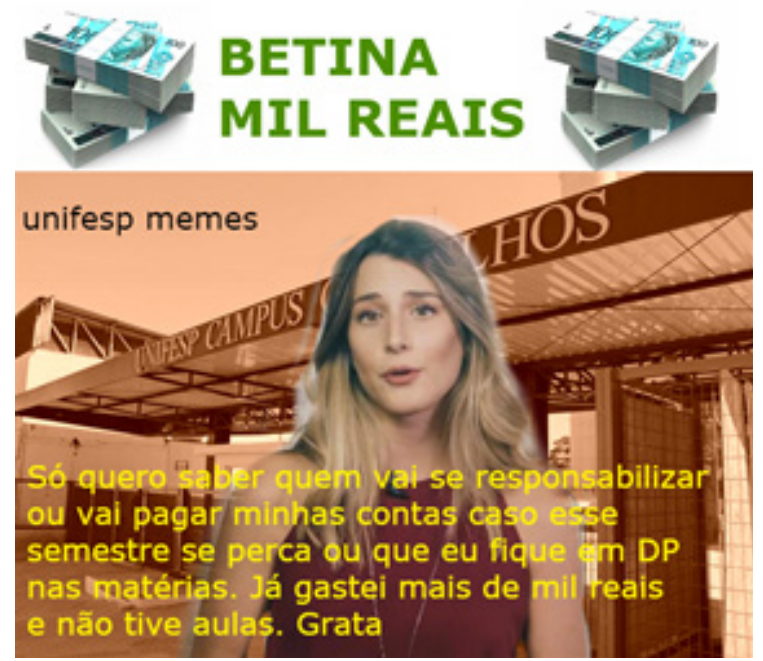

Figura 1. Meme Bettina Mil Reais

A figura acima reproduz um meme publicado no grupo de Facebook do campus de uma universidade pública, com pouco mais de 10.000 inscritos. Nele, vemos a imagem já prontamente identificável de Bettina e, como legenda, os dizeres literais de uma mensagem postada por uma aluna sete anos antes - um "clássico" na comunidade, frequentemente relembrado. Bettina assume aqui a posição enunciativa da aluna e com isso se constitui como voz que formula no discurso uma verdade silenciada pelos anúncios que protagonizou no YouTube: no cotidiano de jovens que pouco se assemelham a Bettina, jovens potenciais devedores, não há dinheiro sobrando para nada além do que já se gasta com os estudos (mesmo numa universidade pública). Não se pode "empreender" quando o investimento primeiro em uma formação acadêmica se vê ameaçado por circunstâncias inesperadas. 


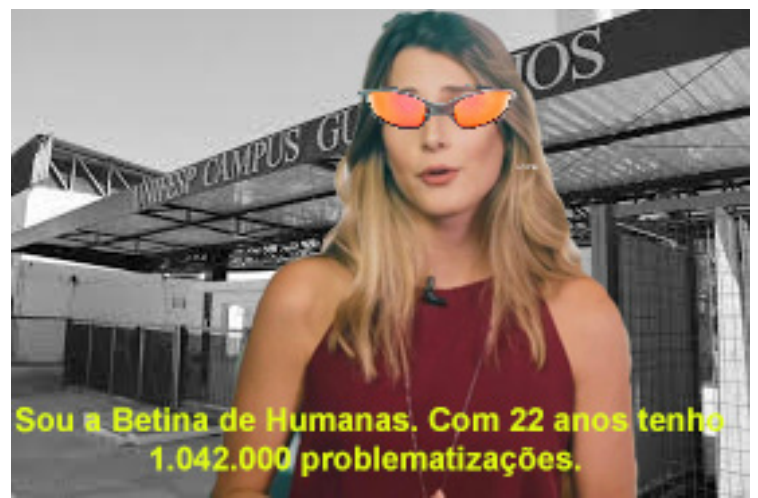

Figura 2. Meme Bettina de Humanas

Este outro meme, surgido no mesmo contexto de produção, traz a imagem de Bettina editada com o acréscimo de óculos de sol, remetendo a um motivo já popularizado em tantos outros memes. Desta vez, o capital acumulado, a partir de um investimento inicial não especificado porém presumível, consiste em mais de 1 milhão de problematizações. Eis um conceito que circula com considerável frequência na formação discursiva acadêmica associada às humanidades. $\mathrm{O}$ efeito de sentido sugerido é o de que problematizações são o legado possível de uma estudante de humanas aos 22 anos. O número exato, correspondente ao patrimônio acumulado por "Bettina de Humanas", é elemento fundamental para cirscunstanciar a resistência à lógica do lucro fácil. Ele é ressignificado aqui para quantificar, pelo exagero, a distância que separa as realidades de Bettina e a de tantos outros jovens que poderiam com ela se identificar.

Numa paródia do canal Guto TV $V^{15}$, no YouTube, Bettina é dublada pelo humorista em cima do vídeo do primeiro anúncio. Nos dizeres iniciais, a paráfrase: "Oi, meu nome é Bettina, tenho 22 anos e tenho 1 milhão e 42 mil reais de dívida acumulado". Na sequência: "Você deve estar se perguntando, 'Como é que essa garota ficou tão $\mathrm{f}^{* * *}$ na vida em tão pouco tempo?’ Mas vai perguntar pra mim, querido? Porque, assim, você é tão f*** quanto eu". A identificação entre esta Bettina e seus interlocutores se dá pelo reverso da narrativa de sucesso e expertise construída pelo vídeo parodiado. A "Bettina vida real" da paródia segue explicando que chegou a tal condição porque emprestava seu cartão de crédito a "todo mundo" e fazia compras sem calcular os valores. Ficou "suja", seu nome tendo ido parar no SPC e no Serasa. Embora sugira que "se você é burra, você vai fazer um acordo 
para pagar a dívida", Bettina termina o vídeo com algum senso de prudência, recomendando a seus ouvintes que tentem pagar suas contas o mais em dia possível. Conselho ainda válido - e que dispensa qualquer conhecimento técnico - porém factível somente para quem dispõe dos recursos.

\section{CONSIDERAÇÕES FINAIS}

O relativamente curto tempo de governo Bolsonaro suscita de nossa parte mais perguntas que respostas no que se refere às formas de populismo predominantes - se as há, conforme a concepção que se adote desse termo. Nossa abordagem aqui propôs o exercício de aplicação instrumental do conceito de populismo, entendido não como uma forma sistemática de política de mobilização das demandas de um povo, genericamente tomado, contra aquelas provenientes das elites. A articulação que sugerimos se dá no espaço entre as políticas econômicas de cunho neoliberal que têm pautado o atual governo desde seu início e a perspectiva de um campo fértil para a proliferação de discursos focados no sujeito como bomo oeconomicus: um sujeito livre para investir não só seu dinheiro, mas seus desejos e subjetividades. Nesse processo, o Estado deixa gradativamente de ser entendido como uma rede de proteção e seguridade sociais, incentivando e promovendo ações de desenvolvimento coletivo. Ele passa a ser visto como espaço "neutro" em que a liberdade individual para empreender e transitar no(s) mercado(s), a partir de recursos próprios, é assegurado a todos, e em "condição de igualdade".

Os vídeos de Bettina são pequenas janelas para essa nova ordem - uma ordem não tão nova no que se refere aos princípios estruturais do neoliberalismo que, afinal, já se mostravam prevalentes no Brasil em governos anteriores, mas uma ordem que ora encontra um horizonte bem mais favorável e acessível para se firmar como hegemônico. O bomo oeconomicus representado por Bettina é o sujeito que está conectado mais do que nunca, e que precisa apenas de alguns "trocados" (1.500 reais, se possível) para investir na bolsa e acumular um patrimônio rentável. Mas, num nível mais fundamental, o bomo oeconomicus é o sujeito que bem pode estar à deriva, desfavorecido por uma política de Estado que se isenta de promover, estruturalmente, a diminuição da desigualdade socioeconômica cujos efeitos concretos sobre as pessoas são obliterados por um discurso que insiste em constituílas como empreendedoras de si mesmas. 


\section{REFERÊNCIAS}

BROWN, W. (2015). Undoing the Demos: Neoliberalism's Stealth Revolution. Nova York: Zone Books.

BROWN, W. (2018). Neoliberalism's Frankenstein. Authoritarian Freedom in TwentiethFirst Century "Democracies". In: Brown, W.; Gordon, P. E.; Pensky, P. Authoritarianism: Three Inquiries in Critical Theory. Chicago e Londres: The University of Chicago Press.

CHUN, C. W. (2016). Exploring Neoliberal Language, Discourses and Identities. In: Preece, S. (org.) The Routledge Handbook of Language and Identity. Londres: Routledge.

HAN, B.-C. (2017). Psychopolitics: Neoliberalism and New Technologies of Power, trad. Erick Butler. Londres e Nova York: Verso.

HARDT, M.; NEGRI, A. (2012). Declaration: This Is Not a Manifesto. Nova York: Argo Navis.

LACLAU. E. (2005). On Populist Reason. Londres e Nova York: Verso.

LORENZINI, D. (2018). Governmentality, Subjectivity, and the Neoliberal Form of Life. In: Journal for Cultural Research, v. 22, n 2, pp. 154-166.

MUDDE, C.; KALTWASSER, C. R. (2017). Populism: A Very Short Introduction. Oxford e Nova York: Oxford University Press.

PÊCHEUX, M. (1997). O discurso: estrutura ou acontecimento, 2a ed. Campinas: Pontes.

RYDGREN, J. (2017). Radical Right-Wing Parties in Europe: What's Populism Got to Do With It? In: Journal of Language and Politics, v. 16, n 4, pp. 1-12 [485-496].

STRAVAKAKIS, Y. (2017). Discourse Theory in Populism Research: Three Challenges and a Dilemma. In: Journal of Language and Politics, v. 16, n . 4, pp. 1-12 [523-534].

Recebido: 20/02/2020

Aceito: 30/04/2020

Publicado: 21/05/2020 